\title{
Effect of Carbonaceous Deposit on Bed Particles During Rapid Pyrolysis on Gasification Rate of Biomass Char in Fluidized Bed
}

\author{
Shunpei Murayama ${ }^{1}$, Toshiyuki Iwasaki ${ }^{1}$, Hideki Suganuma ${ }^{1}$, Shigeru Kato ${ }^{1}$, Shigeo Satokawa ${ }^{1}$, Akihiro \\ Yamasaki $^{1}$, Seiichi Suzuki ${ }^{1} \&$ Toshinori Kojima ${ }^{1}$ \\ ${ }^{1}$ Department of Materials and Life Science, Faculty of Science and Technology, Seikei University, Japan \\ Correspondence: Toshinori Kojima, Department of Materials and Life Science, Faculty of Science and \\ Technology, Seikei University, 3-1 Kichijoji-kitamachi 3-chome, Musashino-shi, Tokyo 180-8633, Japan. Tel: \\ 81-422-37-3750. E-mail: kojima@st.seikei.ac.jp
}

Received: November 29, 2013 Accepted: February 15, 2014 Online Published: April 29, 2014

doi:10.5539/eer.v4n2p80

URL: http://dx.doi.org/10.5539/eer.v4n2p80

\begin{abstract}
Gasification characteristics were evaluated for various biomass samples such as softwoods and hardwoods. They were pyrolyzed at $1000{ }^{\circ} \mathrm{C}$ in a small scale fluidized bed under rapid heating condition with $\mathrm{N}_{2}$ flow. After keeping $10 \mathrm{~min}$ at the temperature, the produced char was gasified with $25 \% \mathrm{CO}_{2}$ at $1000{ }^{\circ} \mathrm{C}$. Char gasification characteristic was investigated by monitoring $\mathrm{CO}$ producing rate and the effects of woody biomass species on gasification rate and its time variation were examined. The conversion rate, $d X / d t$ was plotted against the value of conversion. As a result, the following characteristic curves were observed mainly for softwoods; at nearly conversion $X=0.05$, high reactivity peak was found, $\mathrm{CO}$ production was decreased first rapidly and then slowly until $X=0.5$, and then almost followed volume reaction behavior. In order to elucidate the cause of this phenomenon, the high temperature char with bed material of alumina in the bed was cooled down under the $\mathrm{N}_{2}$ flow to the room temperature and the char and alumina particles were separated by sieving. The alumina particles became black which suggests existence of some carbonaceous materials. Then each sample was introduced into the fluidized bed and separately gasified in the same bed. The gasified gas analyses showed that gasification rapidly proceeded for alumina particles only at the first stage of its gasification which explained the peak of gas evolution at low conversion of the continuous in situ pyrolysis/gasification experiments. In case of hardwoods, the amount of carbonaceous materials remaining in bed materials was quite small and it does not affect the results of the in situ pyrolysis/gasification experiments. Gasification difference of the char separately collected depended on their own properties rather than the common properties in their group.
\end{abstract}

Keywords: fluidized bed, woody biomass char, gasification rate, carbonaceous materials, bed material

\section{Introduction}

Biomass gasification is a promising energy conversion method, which can produce chemicals along with fuels of gas, liquid, and solid phases. The pyrolysis condition of temperature and heating rate should give serious effects on the downstream processes such as combustion and gasification. Among the various high temperature processes, taking the usability of the electricity into the account, the electricity generation by combined cycle using gas produced from biomass is thought to be promising. In order to establish its system, it is needed to know not only the yields and properties of pyrolysis gas, tar and char but also gasification kinetics of char.

For the gasification, though so many papers reported the gasification kinetics and morphology change during the gasification, most of the studies were conducted at relatively low temperature and for chars produced at the slower heating rate than that in commercial continuous fluidized beds or entrained beds. Furthermore most of the char used for gasification reactivity test is prepared in a separate reactor. The various kinds of biomass species have so far been tested by many researchers while under different conditions, so the unified comparison between various kinds of biomass under the unified condition was difficult (Tinaut et al., 2008; Fushimi et al., 2003; Okumura \& Okazaki, 2009; Marquez-Montesinos et al., 2002).

Some papers reported the gasification results of char produced under the rapid heating rate. However the produced char was generally taken out after the char is cooled and then it is again heated up and gasified. Furthermore, in most of the biomass gasification experiments, the number of biomass species are limited (Yuan et al., 2011). 
Gasification step is the last and the slowest step of the high efficient combined power generation from biomass. Hence in our previous study (Murayama et al., 2013), the authors conduct in situ gasification of char produced under the high heating rate in an experimental fluidized bed without cooling by changing the gas from $\mathrm{N}_{2}$ to $25 \%$ $\mathrm{CO}_{2}$. Seventeen biomass samples are gasified and their gasification rates are measured under the unified condition: at the same concentration of gas and at the same temperature of $1000{ }^{\circ} \mathrm{C}$ which is relatively high compared with conditions of experiments so far conducted. Char gasification characteristic was investigated by monitoring $\mathrm{CO}$ producing rate and the effects of woody biomass species on gasification rate and its time variation were examined. The conversion rate, $d X / d t$ was plotted against the value of conversion. As a result, the characteristic curves were observed mainly for softwoods; at nearly conversion $X=0.05$, high reactivity peak was found, CO production was decreased first rapidly and then slowly until $X=0.5$, and then almost followed volume reaction behavior.

In the present study, in order to elucidate the cause of this phenomenon, the high temperature char with bed material of alumina in the bed is cooled down under the $\mathrm{N}_{2}$ flow to the room temperature and char and alumina particles are separated by sieving. Then the gasification behavior of each sample is separately examined in the fluidized bed.

\section{Experimental}

\subsection{Biomass and Bed Materials Samples}

The biomass types we used were four softwoods [pine (Japanese red pine, Pinus densiflora: MATSU), cypress (Japanese cypress, Chamaecyparis obtuse: HINOKI), cryptomeria (Cryptomeria japonica: SUGI), cedar (Cedrus deodara: HIMARAYASUGI)] and three hardwoods [eucalyptus (Eucalyptus camaldulensis: YUKARI), white oak (Quercus myrsinaefolia: SHIRAKASHI), nettle tree (Celtis sinensis var japonica: ENOKI)]. Their average particle diameter was set to be $1.7<\mathrm{d}_{\mathrm{p}}<2.8 \mathrm{~mm}$ by sieving. The physical and chemical properties are shown in Table 1. Porous alumina particles with particle density of $1170 \mathrm{~kg} / \mathrm{m}^{3}$, mean diameter of $215 \mu \mathrm{m}$ were used as fluidized bed materials.

Table 1. Properties of biomass samples used

\begin{tabular}{|c|c|c|c|c|c|c|c|c|c|}
\hline \multirow{2}{*}{ Group } & \multirow[t]{2}{*}{ Biomass species } & \multicolumn{3}{|c|}{$\begin{array}{c}\text { Proximate analysis } \\
\text { (wt } \% \text { dry) }\end{array}$} & \multicolumn{4}{|c|}{ Ultimate analysis (wt $\%$ dry) } & \multirow{2}{*}{ Density } \\
\hline & & $\begin{array}{l}\text { Volatile } \\
\text { Matter }\end{array}$ & $\begin{array}{l}\text { Fixed } \\
\text { Carbon }\end{array}$ & Ash & $\mathrm{C}$ & $\mathrm{H}$ & $\mathrm{N}$ & $\mathrm{O}$ (dif.) & \\
\hline \multirow{4}{*}{ softwood } & pine & 82.18 & 17.25 & 0.57 & 49.40 & 6.33 & 0.14 & 43.56 & 530 \\
\hline & cypress & 84.75 & 15.08 & 0.17 & 48.33 & 5.91 & 0.00 & 45.59 & 430 \\
\hline & cedar & 83.30 & 16.40 & 0.26 & 47.97 & 5.58 & 0.10 & 46.09 & 580 \\
\hline & cryptomeria & 83.39 & 16.41 & 0.20 & 48.69 & 6.09 & 0.00 & 45.02 & 380 \\
\hline \multirow{3}{*}{ hardwood } & eucalyptus & 78.92 & 18.50 & 2.58 & 48.02 & 5.99 & 0.37 & 43.04 & 920 \\
\hline & white oak & 82.90 & 14.70 & 2.40 & 43.99 & 5.72 & 0.18 & 47.71 & 780 \\
\hline & nettle tree & 82.20 & 16.80 & 1.08 & 45.25 & 6.20 & 0.29 & 47.18 & 680 \\
\hline
\end{tabular}

\subsection{Apparatus and Condition}

Figure 1 shows details of the fluidize bed device we used. Experimental conditions are as follows: biomass amount, $250 \mathrm{mg}$ : static bed height, $50 \mathrm{~mm}$; gas flow rate, 6 times of $\mathrm{U}_{\mathrm{mf}}\left(0.0942 \mathrm{~m} / \mathrm{s}\right.$ at $\left.1000{ }^{\circ} \mathrm{C}\right)$; pressure, 1 atm; gasification temperature, $1000{ }^{\circ} \mathrm{C}$. 


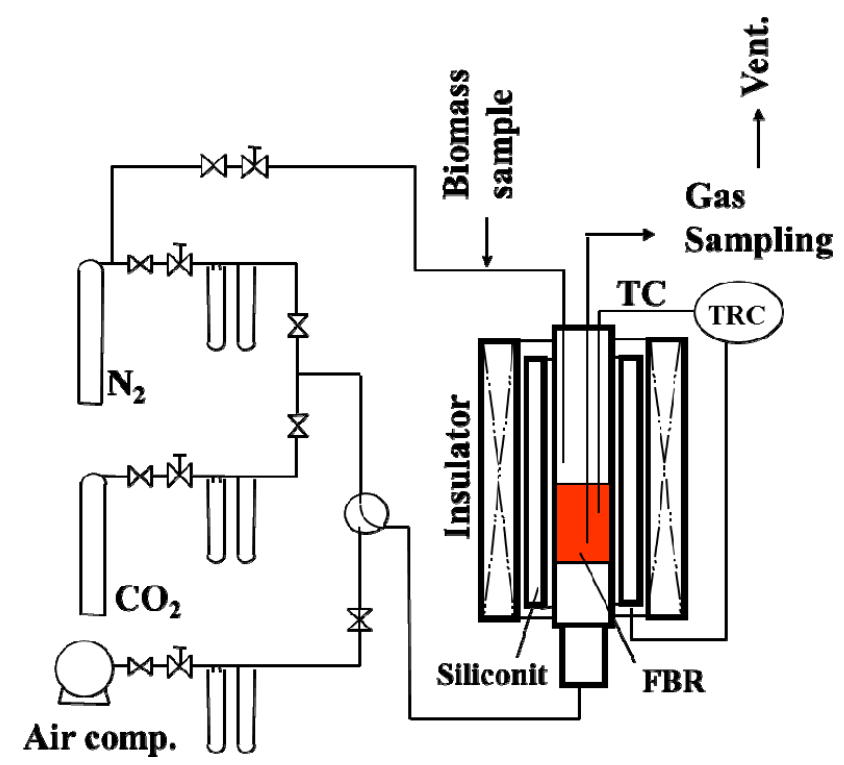

Figure 1. Schematics of fluidixed bed reactor

\subsection{In Situ Gasification}

When biomass samples $\left(1.7<\mathrm{d}_{\mathrm{p}}<2.8 \mathrm{~mm}\right)$ are dropped into the fluidize bed kept at $1000{ }^{\circ} \mathrm{C}$ under $\mathrm{N}_{2}$ atmosphere, the biomass samples are heated rapidly by vividly moving bed materials. According to the numerical calculation of temperature profile inside the particle assuming the spherical shape with constant surface temperature of $1000{ }^{\circ} \mathrm{C}$, we got rapid heating rate of averaged temperature inside the particles up to around $1000^{\circ} \mathrm{C} / \mathrm{s}$ (at the first stage of heating).

After 10 min pyrolysis, the in situ produced char was started to be gasified by introducing $25 \% \mathrm{CO}_{2}$ gas diluted with $\mathrm{N}_{2}$. We sampled produced gas using a $10 \mathrm{~mL}$ syringe from $5 \mathrm{~s}$ to $15 \mathrm{~min}$ intervals for $60 \mathrm{~min}$, and $\mathrm{CO}$ concentration was analyzed by a gas chromatograph. When $\mathrm{O}_{2}$ was detected it was regarded to be caused by the leaking-in of air, and the $\mathrm{N}_{2}$ and $\mathrm{CO}$ concentrations were corrected. The $\mathrm{CO}$ production rate was given by multiplying the molar $\mathrm{N}_{2}$ flow rate by concentration ratio of $\mathrm{CO}$ to $\mathrm{N}_{2}$, and plotted against the time.

\subsection{Separate Gasification of Bed Materials and Char}

After the same procedures of $10 \mathrm{~min}$ pyrolysis as above, the produced char was cooled down to room temperature in $\mathrm{N}_{2}$ atmosphere. All of the char and bed materials were taken out from the bed and separated by a sieve with $355 \mu \mathrm{m}$ opening. The particles passing through $355 \mu \mathrm{m}$ were regarded as a bed materials. The particles larger than $355 \mu \mathrm{m}$ were treated as char without further treatment, though some bed particles were adhering around the char and it may behave like other bed materials.

Then, only the bed material were placed in the fluidize bed again at the room temperature and the bed was heated at $10{ }^{\circ} \mathrm{C} / \mathrm{min}$ in $\mathrm{N}_{2}$ atmosphere. When its temperature was reached to $1000{ }^{\circ} \mathrm{C}, 25 \% \mathrm{CO}_{2}$ gas diluted with $\mathrm{N}_{2}$ was started to be introduced and the produced gas was sampled using a $1 \mathrm{~mL}$ syringe at $5 \mathrm{~s}$ to $15 \mathrm{~min}$ intervals for $60 \mathrm{~min}$. And $\mathrm{CO}$ concentration was analyzed by a gas chromatograph as above. After the gasification experiment, air was introduced to the bed at $1000{ }^{\circ} \mathrm{C}$ and cooled down. After the bed was sufficiently cooled, the char were dropped into the fluidized bed and the temperature was again heated at $10{ }^{\circ} \mathrm{C} / \mathrm{min}$ in $\mathrm{N}_{2}$ atmosphere with clean bed material. When its temperature reached to $1000{ }^{\circ} \mathrm{C}$, the char was started to be gasified by introducing $25 \% \mathrm{CO}_{2}$ gas diluted with $\mathrm{N}_{2}$. We sampled produced gas using a $1 \mathrm{~mL}$ syringe at $5 \mathrm{~s}$ to 15 min. intervals for $60 \mathrm{~min}$, and $\mathrm{CO}$ concentration was analyzed by a gas chromatograph.

\subsection{Analyses}

For all of the three types of experiments, namely, in situ gasification, and two types of separate gasifications of bed materials and char, the following analyses were conducted. From the time variation curve of an experiment, we calculated char conversion and conversion rate assuming $\mathrm{C}+\mathrm{CO}_{2} \rightarrow 2 \mathrm{CO}$. Hence the molar amount of carbon converted is given as the half of the accumulated value of time variation of $\mathrm{CO}$ produced, $f_{\mathrm{CO}}$, and calculated by trapezoidal integration. The total carbon gasified was given from the above integration through the experiment. The conversion at a time, $X$, is given by dividing the integrated value of $\mathrm{CO}$ produced until the time, 
$t$, by the total carbon gasified. The half value of $\mathrm{CO}$ produced at the time, $t$, was divided by the value of total carbon gasified, and this give the conversion rate at the time, $d X / d t$.

\section{Results and Discussion}

\subsection{In Situ Gasification}

The typical time variation data of $\mathrm{CO}$ produced by $\mathrm{CO}_{2}$ gasification are shown in Figure 2 for four kinds of softwoods and in Figure 3 for three kinds of hardwoods. In both cases, it can be seen that after first rapid increase in the $\mathrm{CO}$ release, its production rate is found to be rapidly decreased and then gradually approach to zero, while some difference is observed between for softwoods and for hardwoods.

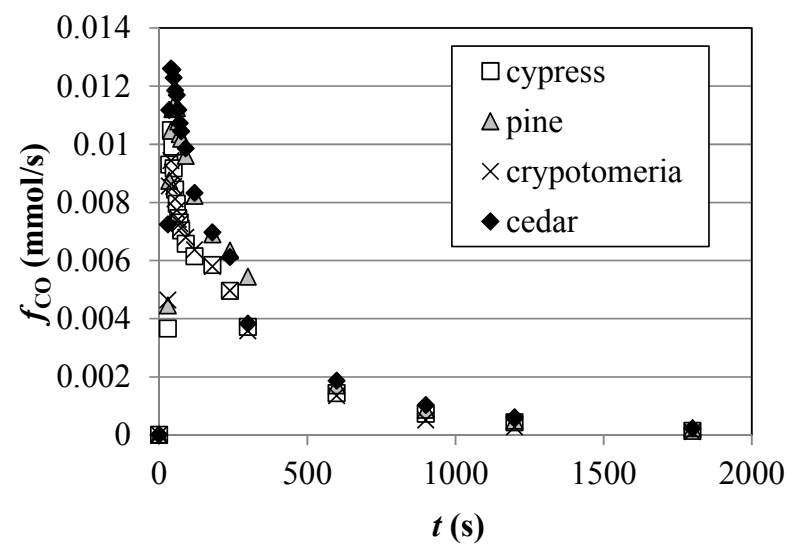

Figure 2. Typical time variation of produced $\mathrm{CO}$ (softwoods)

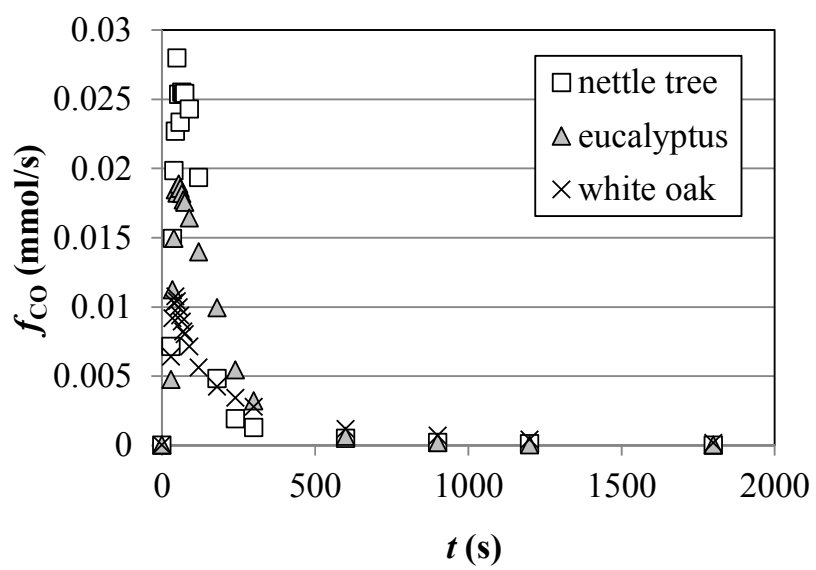

Figure 3. Typical time variation of produced CO (hardwoods)

In case of this series of experiments, several iterated experiments were conducted, so the averaged $d X / d t$ vs. $X$ curve were calculated to get their relation as shown in Figures 4 and 5 respectively for softwoods and hardwoods. In case of softwood chars gasification in Figure 4, the gasification procedure is divided into three periods with the progress of conversion of $X$. At nearly $X=0.05$, high reactivity peak is found and CO production is decreased rapidly beyond the peak. Between around $X=0.1$ and $X=0.5, \mathrm{CO}$ production is decreased slowly. After $X=0.6$, the lines are almost regarded as straight lines which indicates the reaction nearly follows volume reaction model.

As shown in Figure 5, while the reaction characteristics and absolute rates are quite different among three hardwoods, and only the two species showed larger gasification rate than those for softwoods, it is commonly characterized that the peak values of $d X / d t$ are observed at smaller value of conversion, $X$, than those of softwoods. Generally for hardwoods, especially for eucalyptus and nettle tree, gasification rates of $d X / d t$ are kept high until higher value of conversion, $X$, than softwoods. Though white oak shows almost similar reaction rate tendency to softwood, namely the rate is dropped after the peak, the peak is found still at higher conversion than 
softwoods. In order to elucidate the difference found between two groups of softwoods and hardwoods, and within the hardwood group, we measured gasification rates of bed materials of alumina particles and biomass char separately.

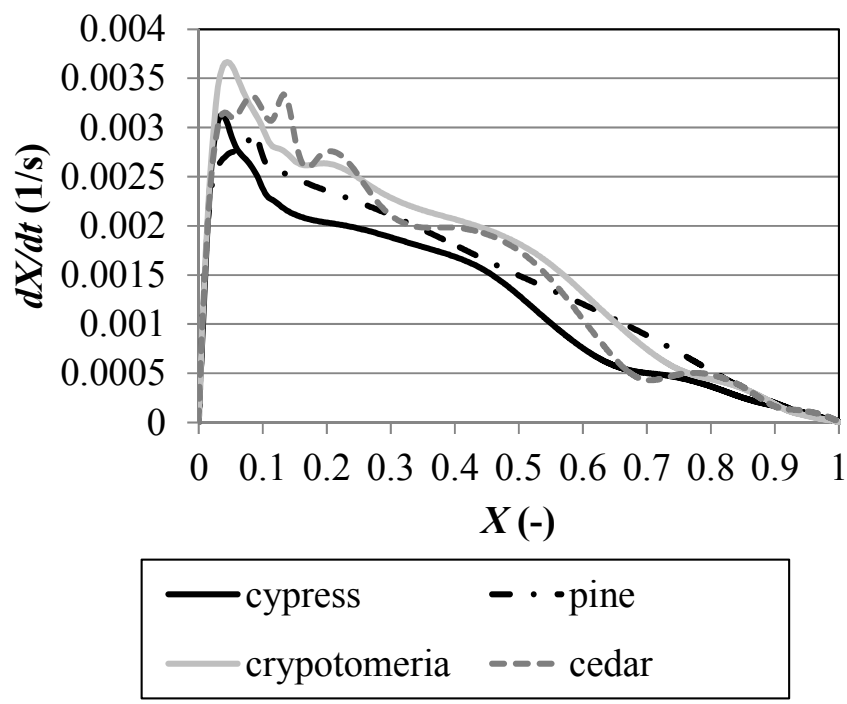

Figure 4. Averaged $d X / d t$ vs. $X$ curve (softwood)

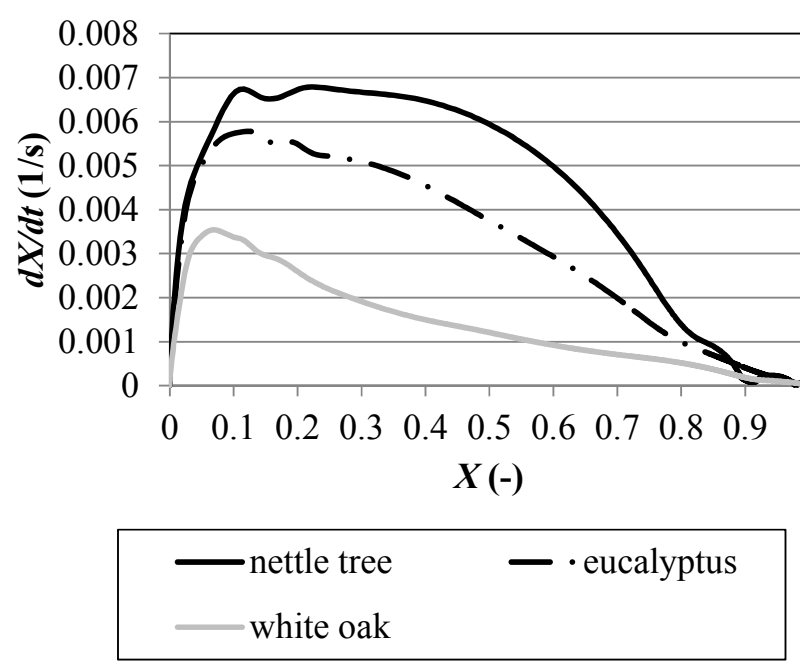

Figure 5. Averaged $d X / d t$ vs. $X$ curve (hardwoods)

\subsection{Separate Gasification of Bed Materials and Char: Softwood}

Figure 6 shows time variation of $\mathrm{CO}$ produced from gasification of only char produced from softwood pyrolysis followed by cooling and separation. Production speeds of $\mathrm{CO}$ from the separated chars are different among several biomass species, while those in Figure 2 look almost same among them. Cypress shows the maximum $\mathrm{CO}$ production of $2 \mu \mathrm{mol} / \mathrm{s}$ at $200 \mathrm{~s}$, Cedar, $7 \mu \mathrm{mol} / \mathrm{s}$ and others, $4 \mu \mathrm{mol} / \mathrm{s}$ at $100 \mathrm{~s}$. But the maximum values were much lower than those in Figure 2 (almost less than half: in case of cypress, less than quarter), and furthermore the peak position was sifted to higher conversion. 


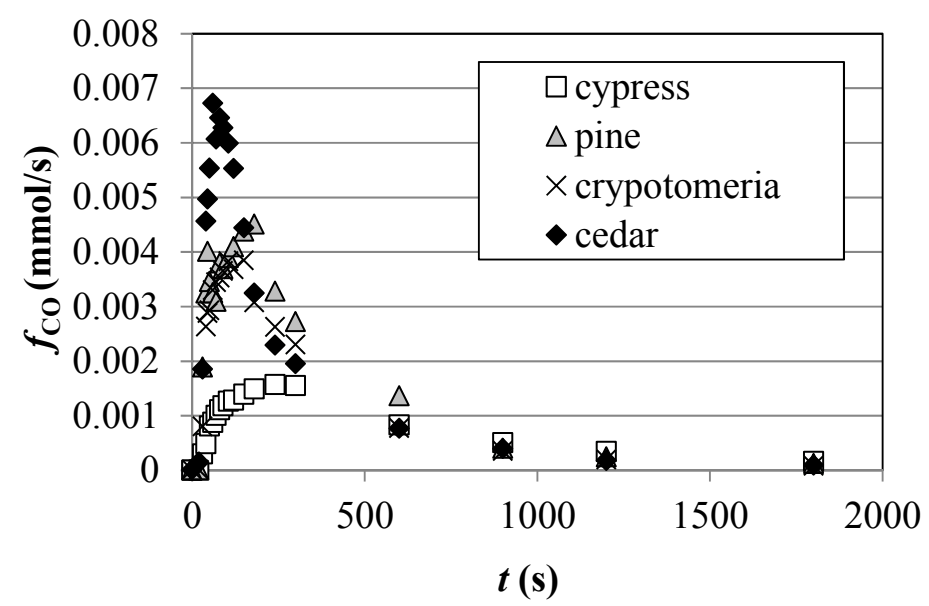

Figure 6. Time variation of produced CO (softwoods, char only without bed materials)

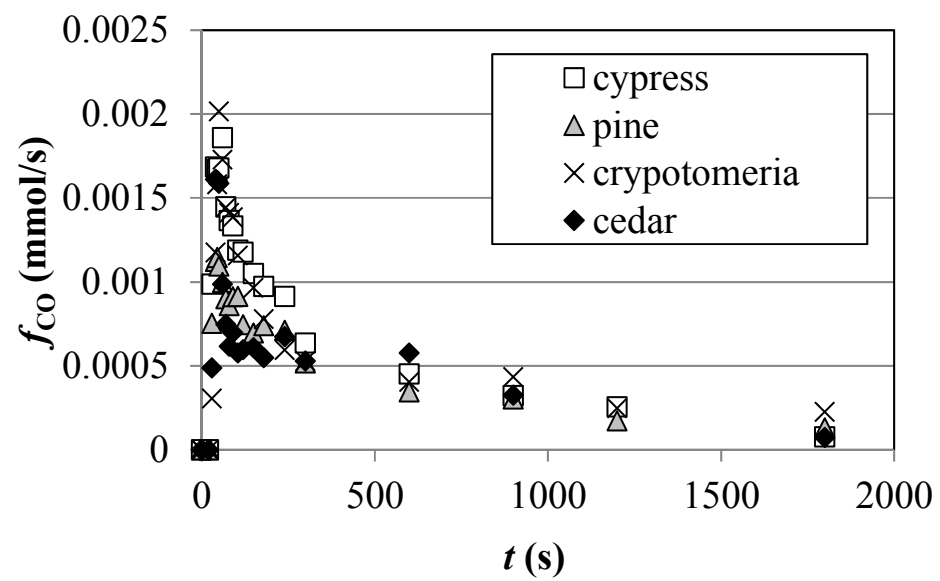

Figure 7. Time variation of produced CO (softwoods, only bed materials of alumina)

On the other hand, as shown in Figure 7, CO production from residual alumina particles used for cypress pyrolysis has almost same size peak as that from char gasification only. Though, the data for others have much smaller peaks than those from char only, these peaks locate at comparably initial period of gasification as those in Figure 2 ( $50 \mathrm{~s}$ or earlier). Namely, the CO peaks found at the earliest stage of gasification shown in Figure 2 or those at around $X=0.05$ in Figure 4 are explained by rapid $\mathrm{CO}$ production by gasification of carbonaceous materials kept in the alumina bed materials.

Figure 8 and Figure 9 show $d X / d t$ vs $X$ relations for softwoods, corresponding to Figures 6 and 7, respectively. Because $X$ values in these figures are calculated based on total CO released from reaction of char and alumina bed particles only, respectively, they show only their reactivity.

Comparing Figures 8 and 9 , all of the data of only char gasification and only bed materials gasification show almost similar reactivity after $X=0.6$ and higher reactivity is found at lower conversion. Much more difference between species is found in Figure 8 showing the gasification of char only than in Figure 9 showing gasification of alumina only. In case of bed material gasification, reactivity is high only at very low conversion while in case of char gasification high reactivity is kept relatively until higher conversion. 


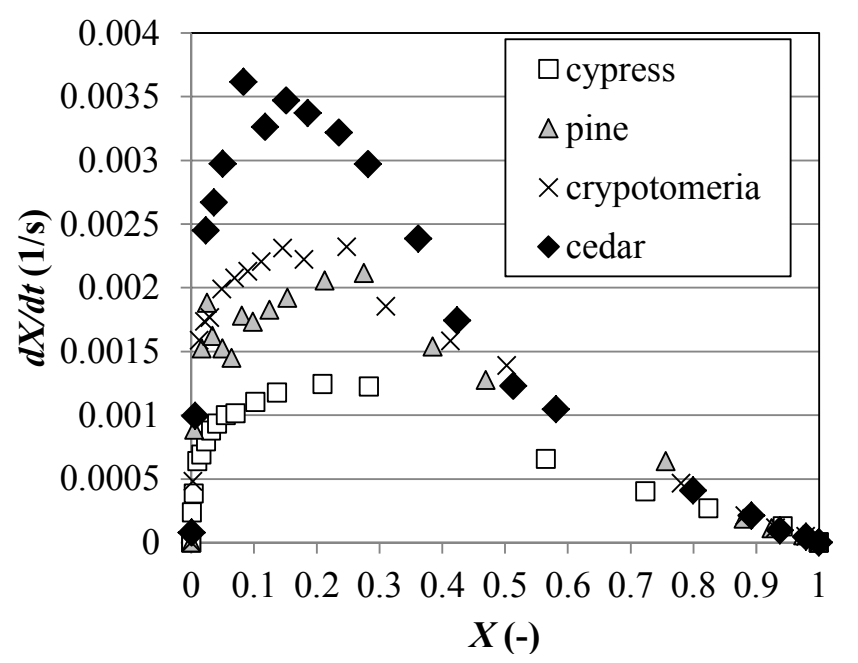

Figure $8 . d X / d t$ vs. $X$ curve (softwoods, char only without bed materials)

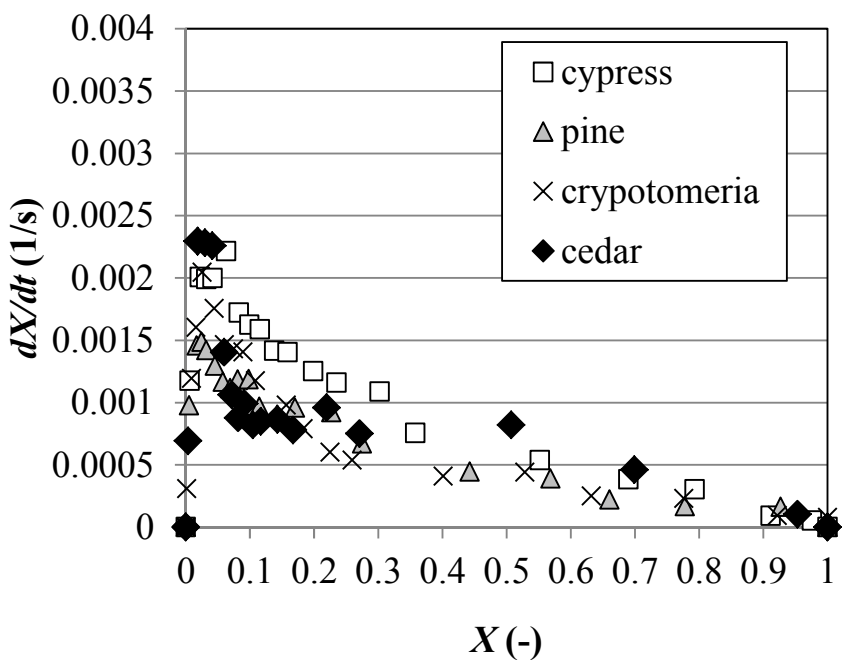

Figure 9. $d X / d t$ vs. $X$ curve (softwoods, only bed materials of alumina)

Considering the above results, small amount of tar or some reactive materials remained in alumina pores and showed rapid gasification at first stage but most of the components have low reactivity. On the other hand, the char only is suggested to have two parts: one is almost half high reactive part and almost half less reactive part which has almost same reactivity as main part of carbonaceous materials in alumina. Furthermore the reactivity of the half reactive part has species dependency. But for example, in case of cypress char, with the lowest reactivity among four softwoods, the most amount of $\mathrm{CO}$ is produced from alumina. Hence there could hardly be found the difference among four softwoods in Figures 2 or 4. In Figure 4, the first peak part corresponds to the reactive part of carbonaceous materials in alumina, and second part to the reactive part of char and last part, less reactive parts of both of char and alumina.

\subsection{Separate Gasification of Bed Materials and Char: Hardwood}

Figure 10 and Figure 11 show time variations of CO produced from gasification of only char and alumina particles only respectively, produced from hardwood pyrolysis followed by cooling and separation. The peaks of CO production speed from only char gasification were about ten times of those from gasification of carbonaceous materials in bed materials, while the peaks from bed materials locate at the initial stage of gasification, which tendency is same as that for softwoods. 


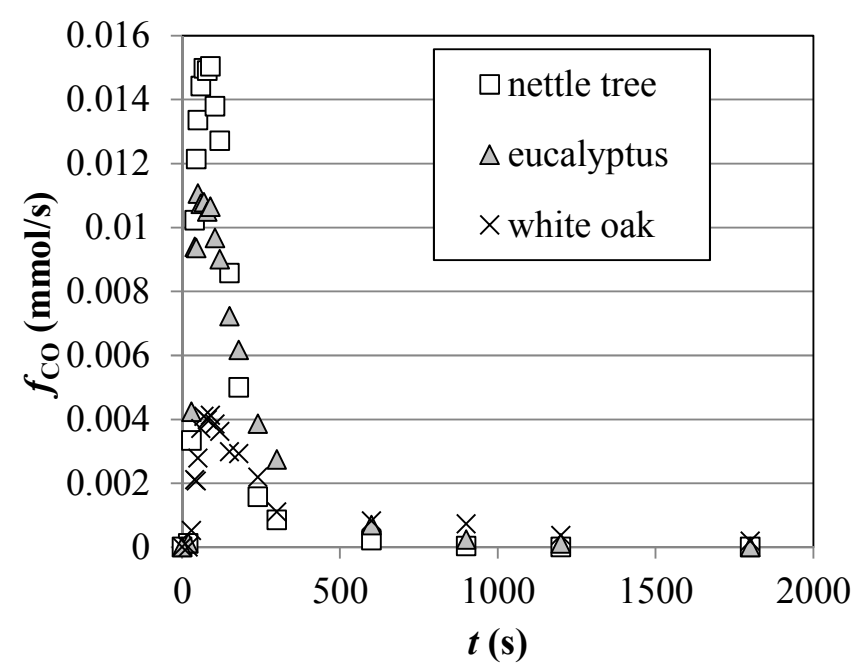

Figure 10. Time variation of produced CO (hardwoods, char only without bed materials)

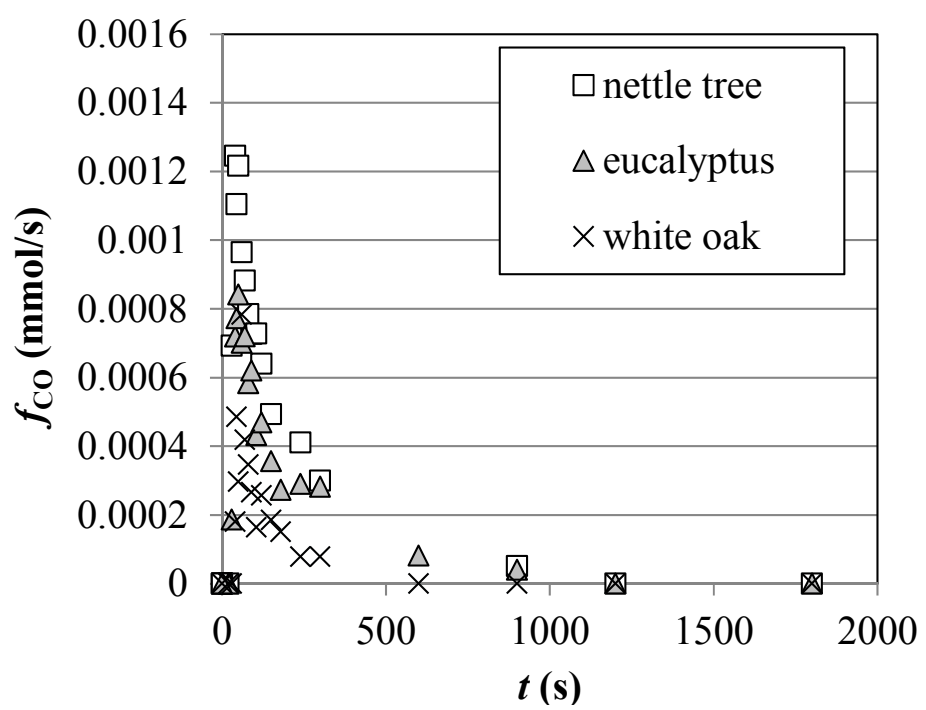

Figure 11. Time variation of produced CO (hardwoods, only bed materials of alumina)

Figures 12 and 13 show $d X / d t$ vs. $X$ relations for hardwoods, corresponding to Figures 10 and 11, respectively. Though same note is necessary as softwoods, namely, $X$ values in these figures are calculated based on total CO released from reaction of char and alumina bed particles only, the tendency in Figure 12 is almost same as Figure 5 , which is explained by the fact that the $\mathrm{CO}$ produced from gasification of bed materials is quite less than that from gasification of char. The gasification reactivity of carbonaceous materials in bed materials of alumina for hardwoods is generally higher than that for softwoods, by comparing Figures 13 and 9 . By comparing all of char gasification reactivity data in Figures 12 and 8, though the averaged gasification rate of hardwoods is higher than that of softwoods, it is not unified conclusion. The difference depended on their own properties rather than the group. 


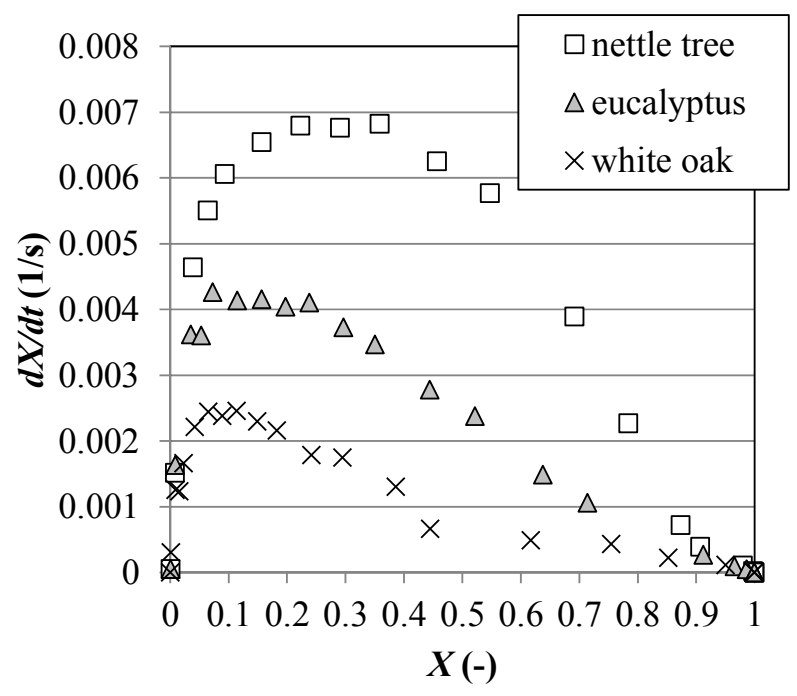

Figure 12. $d X / d t$ vs. $X$ curve (hardwoods, char only without bed materials)

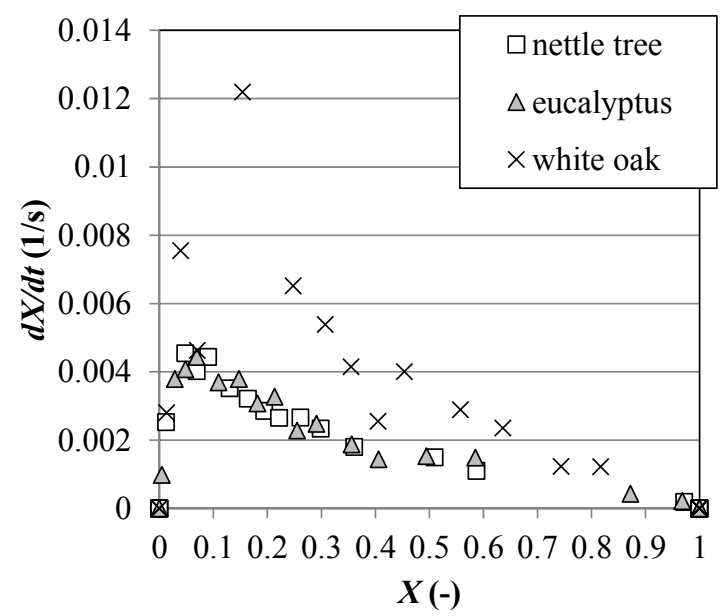

Figure 13. $d X / d t$ vs. $X$ curve (hardwoods, only bed materials of alumina)

\section{Conclusions}

In case of softwood chars gasification, at nearly $X=0.05$, high reactivity peak was found and CO production was decreased rapidly beyond the peak. In the $\mathrm{CO}$ production from residual alumina particles gasification, the $\mathrm{CO}$ peak was found at the earliest stage of gasification. Rapid CO production by gasification of carbonaceous materials kept in the alumina bed materials at the initial stage of their gasification suggested that small amount of tar or reactive materials remaining in alumina pores showed rapid gasification at first stage but most of the components had low reactivity. On the other hand, the char only was suggested to have two parts: one is almost half high reactive part and almost half less reactive part which has almost same reactivity as main part of carbonaceous materials in alumina.

In case of the hardwoods, the peaks from bed materials locate at the initial stage of gasification, which tendency is same as that for softwoods. But the amount of $\mathrm{CO}$ production from only char gasification was about ten times of those from gasification of carbonaceous materials in bed materials and the gasification tendency of char only was almost same as that of in situ gasification.

By comparing all of gasification reactivity data of char from all of the wood species, though the averaged gasification rate of hardwoods was higher than that of softwoods, it was not unified conclusion. The difference depended on their own properties rather than the group. 


\section{References}

Fushimi, C., Araki, K., Yamaguchi, Y., \& Tsutsumi, A. (2003). Effect of heating rate on steam gasification of biomass. 2. Thermogravimetric-mass spectrometric (TG-MS) analysis of gas evolution. Industrial \& Engineering Chemistry Research, 42(17), 3929-3936. http://dx.doi.org/10.1021/ie0300575

Marquez-Montesinos, F., Cordero, T., Rodriguez-Mirasol, J., \& Rodriguez, J. J. (2002). CO 2 and steam gasification of a grapefruit skin char. Fuel, $423-429$. http://dx.doi.org/10.1016/S0016-2361(01)00174-0

Murayama, S., Iwasak, T., Suganuma, H., Kato, S., \& Kojima, T. (2013). Effect of Woody Biomass Type on Gasification Rate of Char Produced by Fluidized Bed Rapid Pyrolysis-. APCSEET, The 9th Asia Pacific Conference on Sustainable Energy \& Environmental Technologies, 5(Fri.)-8(Mon.) July, Narita, Japan.

Okumura, Y., \& Okazaki, K. (2009). Pyrolysis and gasification experiments of biomass under elevated pressure condition. Journal of Environment and Engineering, 4(1), 24-35. http://dx.doi.org/10.1299/jee.4.24

Tinaut, F. V., Melgar, A., Perez, J. F., \& Horrillo, A. (2008). Effect of biomass particle size and air superficial velocity on the gasification process in a downdraft fixed bed gasifier. An experimental and modelling study. Fuel Processing Technology, 89(11), 1076-1089. http://dx.doi.org/10.1016/j.fuproc.2008.04.010

Yuan, S., Chen, X. L., Li, J., \& Wang, F. C. (2011). $\mathrm{CO}_{2}$ gasification kinetics of biomass char derived from high-temperature rapid pyrolysis. Energy \& Fuels, 25(5), 2314-2321. http://dx.doi.org/10.1021/ef200051z

\section{Copyrights}

Copyright for this article is retained by the author(s), with first publication rights granted to the journal.

This is an open-access article distributed under the terms and conditions of the Creative Commons Attribution license (http://creativecommons.org/licenses/by/3.0/). 